16 a 18 de outubro de 2019 - Campinas | Brasil

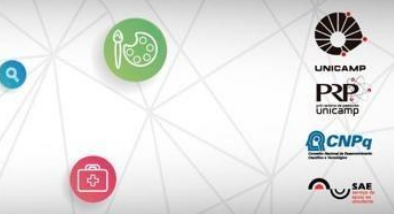

\title{
As Políticas Públicas de combate e controle da Dengue e de seu vetor Aedes aegypti no Brasil
}

\section{Júlia Sanches Baptista*, André Luiz Sica de Campos.}

\section{Resumo}

O projeto estabeleceu como principal objetivo executar um breve estudo sobre o Programa Nacional de Controle da Dengue (PNCD), do ano de 2002, considerando as perspectivas históricas da evolução das políticas públicas de combate ao Aedes aegypti no Brasil, do complexo processo de urbanização brasileiro e da criação do Sistema Único de Saúde (SUS) como partes importantes na construção do programa e para a inserção da temática no debate público.

\section{Palavras-chave:}

Dengue, Aedes aegypti, políticas públicas

\section{Introdução}

O mosquito hematófago Aedes aegypti, vetor do vírus da dengue e de outras arboviroses, encontrou nos meios urbanos um ambiente extremamente favorável para a manutenção da espécie. No Brasil, além do clima quente e úmido, as configurações das grandes cidades e o processo de crescimento destas adicionaram fatores que contribuem para manter a proliferação do mosquito no debate de saúde pública. Com estas circunstâncias em mente, o trabalho abordou as ações dos governos federais ao longo do século XX que resultaram na criação do Plano Nacional de Controle da Dengue.

\section{Resultados e Discussão}

As mudanças demográficas ocorrida no país, observadas principalmente no século $\mathrm{XX}$, e o modo como se deram favoreceram a consolidação do vetor Aedes aegypti. A demanda por trabalhadores proporcionou um intenso fluxo em direção às cidades na década de 40 , resultado do vigoroso processo de industrialização e urbanização que seria intensificado e tomaria corpo nas décadas seguintes. Santos (1993) descreveu a urbanização brasileira como um processo heterogêneo e desunificado. Este crescimento acelerado e pouco organizado das cidades provocou lacunas no provimento de condições adequadas de saneamento básico, moradia e saúde, especialmente aos trabalhadores urbanos, proporcionando assim o surgimento de novos criadouros a partir dos dejetos residenciais e industriais (SILVA, 2007, apud COSTA, 2002). Mendonça et al. (2009) ainda discutem sobre o surgimento e o descarte dos derivados de petróleo

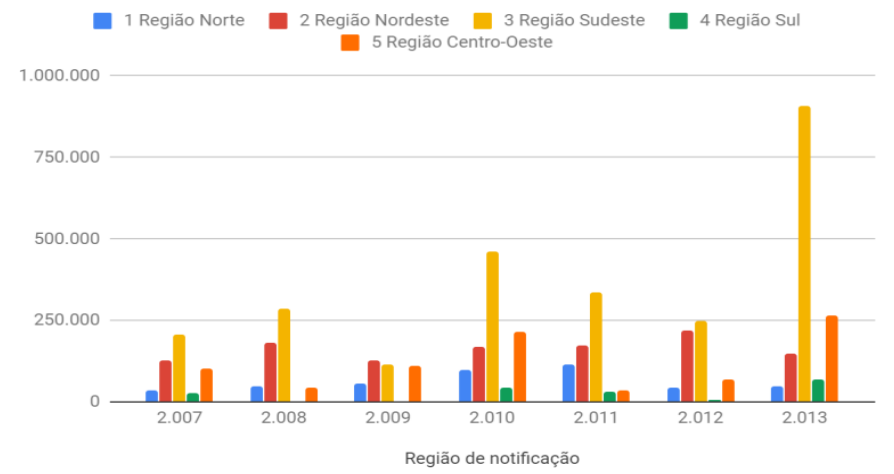

Figura 1. "Número de casos notificados entre 2007 e 2013"; FONTE: Datasus

A partir dos anos 1960 a porcentagem de brasileiros com domicílios urbanos passou a ser maioria com significativa margem de diferença. A tendência continua ao longo do século, acumulando uma concentração demográfica principalmente na Região Sudeste, que é também hoje a Região de maior incidência da dengue, como indica a tabela anterior. Ao longo do século XX foram criados programas pontuais de combate ao Aedes aegypti. Entretanto, apenas na década de 1990 com a redemocratização e a criação do Sistema Único de Saúde que o tema é efetivamente estabelecido nas discussões de saúde pública através da materialização de dois planos: o Programa de Erradicação do Aedes aegypti - PEAa (1996) e o Programa Nacional de Combate a Dengue - PNCD.

\section{Conclusões}

Apesar dos esforços e dos avanços, os programas não conseguiram cumprir com seus principais objetivos. A reformulação do PEAa, que se transforma no PNCD, foi o reconhecimento da complexificação da situação da dengue no Brasil, o que também é refletido na complexificação das condições de moradias urbanas, do trabalho da própria saúde pública. Assim, quando Santos (1993) discorre sobre a divisão territorial do trabalho no Brasil, abre igualmente a discussão para a formulação de políticas públicas, especialmente quando refere-se a uma doença tão fortemente ligada às cidades. A urbanização brasileira não foi uniforme, há ainda hoje diferenças regionais que são fruto das distintas formas e motivações que esta se deu. Portanto, uma abordagem multissetorial que leve em consideração a heterogeneidade dos grandes centros urbanos, bem como as condições históricas que afetam o presente, é um ponto de partida a ser considerado.

BRASIL, Ministério da Saúde, Fundação Nacional de Saúde. Plano Nacional de Controle da Dengue. Ministério da Saúde - Fundação Nacional de Saúde (FUNASA), julho/2002. Disponível em < http://bvsms.saude.gov.br/bvs/publicacoes/pncd_2002.pdf>

SANTOS, Milton. A Urbanização Brasileira. São Paulo: Hucitec, 1993.

SILVA, Jesiel Souza; MARIANO, Zilda de Fátima; SCOPEL, Irací. A Dengue no Brasil e as Políticas Públicas de Combate ao Aedes aegypti: da tentativa de erradicação às Políticas de Controle. Hygeaia - Revista Brasileira de Geografia Médica e da Saúde 3(6): 163-175, Jun/2008. Disponível em <http://www.seer.ufu.br/index.php/hygeia/article/viewFile/16906/9317>

MENDONÇA, Francisco de Assis; SOUZA, Adilson Veiga e; DUTRA, Denecir de Almeida. Saúde Pública, Urbanização e Dengue no Brasil. Sociedade \& Natureza, Uberlândia, 21 (3): 257-269, dez. 2009. Disponível: <http://www.scielo.br/pdf/sn/v21n3/a03v21n3> 